\title{
A IMPORTÂNCIA DO ESTUDO DAS IMPLICAÇÕES ENTRE A FORMAÇÃO DE VÍNCULOS INTERSUBJETIVOS E O DESENVOLVIMENTO DA AFETIVIDADE HUMANA: UMA PROPOSTA TEÓRICA
}

THE IMPORTANCE OF STUDYING THE IMPLICATIONS BETWEEN THE FORMATION OF INTERSUBJECTIVE BONDS AND THE DEVELOPMENT OF HUMAN AFFECTIVITY: A THEORETICAL PROPOSAL

\section{LA IMPORTANCIA DEL ESTUDIO DE LAS IMPLICACIONES ENTRE LA FORMACIÓN DE VÍNCULOS INTERSUBJETIVOS Y EL DESARROLLO DE LA AFECTIVIDAD HUMANA: UNA PROPUESTA TEÓRICA}

\section{Paulo Vinicius Bachette Alves Viana* \\ Reinaldo Furlan ${ }^{* *}$}

\begin{abstract}
RESUMO
No âmbito da Psicologia do desenvolvimento, têm-se realizado pesquisas que buscam investigar os processos desenvolvimentais em suas dimensões cognitivas, sociais e biológicas em todo o ciclo da vida. Nesse contexto, este trabalho buscou evidenciar o papel destacado da afetividade como dimensão essencial no processo desenvolvimental do sujeito, já que esta parece se situar no cerne da vida social, conferindo significação e sentido para a existência. Com base em alguns marcadores em Bowlby e Wallon que situam a emergência do psíquico sobre a base biológica e o caráter relacional-afetivo desse processo, buscamos as implicações entre a formação de vínculos intersubjetivos e o desenvolvimento da afetividade humana, destacando as reflexões de Merleau-Ponty e Philippe Rochat sobre a Psicologia do desenvolvimento infantil.
\end{abstract}

Palavras-chave: Psicologia do desenvolvimento infantil. Afetividade. Vínculos. Intersubjetividade.

\begin{abstract}
In the field of Developmental Psychology, researches have been carried out aiming at investigating developmental processes in their cognitive, social and biological dimensions throughout the life cycle. Within this context, this study aimed to highlight the outstanding role of affection as an essential dimension in the subject's developmental process, as this seems
\end{abstract}

Texto recebido em 4 de outubro de 2016 e aprovado para publicação em 26 de fevereiro de 2018.

Mestrando pela Faculdade de Filosofia Ciências e Letras de Ribeirăo Preto. E-mail: paulobac1@gmail.com.

"* Doutor em Filosofia pela Universidade Estadual de Campinas, mestre em Filosofia pela Universidade Federal de São Carlos, graduado em Filosofia pela Pontifícia Universidade Católica de Campinas, realizou estágio de pós-doutoramento na Universidade Jean Moulin, Lyon 3, França, com bolsa FAPESP e colaboração de Étienne Bimbenet. E-mail: reinaldof@ffclrp.usp.br. 
to lie in the core of social life, giving meaning and direction to life. Based on some markers in Bowlby and Wallon that place the emergence of the psychic on the biological basis and the relational-affective character of this process, we mean to look for the implications between the formation of intersubjective bonds and the development of the human affectivity, highlighting the reflections of Merleau-Ponty and Philippe Rochat on the child developmental Psychology.

Keywords: Child developmental Psychology. Affection. Bonds. Intersubjectivity.

\section{RESUMEN}

En el ámbito de la Psicología del desarrollo se han realizado pesquisas que tratan de investigar los procesos de desarrollo en sus dimensiones cognitivas, sociales y biológicas a lo largo del ciclo vital. En este contexto, el estudio buscó poner de relieve el importante papel de la afectividad como dimensión esencial en el proceso de desarrollo del sujeto, ya que esta parece ubicarse en el centro de la vida social, confiriendo significación y sentido a la existencia. A partir de algunos marcadores en Bowlby y Wallon que sitúan la emergencia de lo psíquico sobre la base biológica y el carácter relacionalafectivo de este proceso, buscamos las implicaciones entre la formación de vínculos intersubjetivos y el desarrollo de la afectividad humana, destacando las reflexiones de Merleau-Ponty y Philippe Rochat sobre la Psicología del desarrollo infantil.

Palabras clave: Psicología del desarrollo infantil. Afectividad. Vínculos. Intersubjetividad.

\section{INTRODUÇÃO}

$\mathrm{N}$

a Psicologia do desenvolvimento, têm se realizado pesquisas que buscam investigar os processos desenvolvimentais em suas dimensões cognitivas, sociais e biológicas em todo o ciclo da vida. Entre os principais assuntos investigados em âmbito nacional, encontram-se questôes epistemológicas, constituição da subjetividade e do sujeito, processos de desenvolvimento no ciclo vital, contextos do desenvolvimento na família, desenvolvimento cognitivo e linguagem, desenvolvimento afetivo e sócio cognitivo, gênero e desenvolvimento, desenvolvimento e saúde (Mota, 2005). Percebe-se que, embora a produção científica na área do desenvolvimento mantenha a afetividade presente em seu campo de interesses, esta tem partido de outras perguntas e salientado outras questões, as quais, conquanto tenham interlocuções com esse conteúdo, não se direcionam a ele de modo direto. 
Essa circunstância faz com que a investigação da afetividade e da formação dos vínculos se torne um assunto a ser revisitado, de modo a avançar na produção de conhecimento sobre essa questão em âmbito nacional, aprofundando em seu mapeamento e esclarecendo o seu papel em conjunto com as outras dimensóes da experiência desenvolvimental humana. Observa-se que, embora se verifique a presença de uma linha de estudos sobre afetividade, esta tem enfatizado, em suas investigações, sobretudo aspectos educacionais e sociocognitivos (Almeida, 1999; Arantes, 2003; Sisto, Boruchovitch, \& Fini, 2001; Tassoni, 2000). Dessa maneira, o propósito geral deste trabalho consiste em situar e esclarecer alguns aspectos referentes à formação e desenvolvimento da dimensão afetiva humana com ênfase no período infantil. Pretende-se explorar, mais detidamente, a afetividade com vistas a esclarecer a relevância que esta assumiria no estabelecimento de vínculos interpessoais e na formação da subjetividade no contexto desenvolvimental do indivíduo. E, nesse sentido, o objetivo específico deste trabalho é fazer uma revisão de literatura fundamentada na obra de MerleauPonty, particularmente em seus estudos sobre a Psicologia do desenvolvimento infantil, que se concentram na série de seus cursos ministrados na Sorbonne, entre 1949 e 1952, e que deram origem ao livro Psychologie et pédagogie de l'enfant, Cours de Sorbone 1949-1952 (Merleau-Ponty, 2001), e orientar-se para o encaminhamento dessa questão mediante contribuiçôes presentes nas obras de autores da Psicologia contemporânea, como Rochat (2002), que, de alguma forma, prolongam essa perspectiva de pesquisa de destaque da dimensão afetiva para o desenvolvimento humano.

As observações e análises aqui realizadas se apoiam em aportes da Filosofia fenomenológica, que considera que não há verdade que não tenha uma dimensão subjetiva, de modo que ela necessita ser apropriada, tornada algo próprio, nossa propriedade (Folscheid \& Wunenburger, 1997).

Isso posto, pontua-se que Merleau-Ponty assume uma perspectiva globalizante de compreensão do fenômeno afetivo. Ele se opõe a cisões no que se refere à investigação das dimensões cognitivas e afetivas do desenvolvimento humano, colocando-se em oposição a elas, de maneira favorável a uma abordagem integrada, contrária ao atomismo ou ao estudo dos elementos isolados do todo, propondo a busca de unidades de análise que mantenham as propriedades da totalidade. 


\section{RELAÇÕES ENTRE AS DIMENSÕES BIOLÓGICA, AFETIVA E SOCIAL}

Adentrando no tema proposto por este trabalho, destacamos a conceituação de afetividade feita por Wallon (1995), que a descreve como a capacidade individual do sujeito de experimentar um conjunto de fenômenos considerados como tendências, emoções, paixões e sentimentos. Para Wallon, a afetividade consistiria, mais precisamente, na força exercida por esses fenômenos sobre o caráter de um indivíduo. Dada essa definição, interessa-nos verificar como surge, desenvolve-se e a que fins se presta a dimensão afetiva, segundo os autores que privilegiamos para este trabalho, os quais se situam na linha de pesquisa afirmada por Merleau-Ponty sobre o desenvolvimento infantil.

Segundo Mazis (1999), Merleau-Ponty faz algumas ponderações sobre esses termos, de modo a salientar o que considera como tensões próprias à dinâmica das emoções. Ele critica a tradição ocidental que desvaloriza a emoção, tratando-a como um simples problema de passividade. Mazis explana que, dentro de sua acepção etimológica, a palavra emoção remonta a "ex-movere", que significa mover-se em direção ao mundo exterior, para fora de si. Assim, a emoção configuraria um movimento para fora de si, ao mesmo tempo em que somos aportados pelo mundo e tocados em profundidade, ou seja, reenviados à nossa própria identidade. Mazis (1999) também comenta sobre o termo feeling (sentimento), explanando que este remonta ao termo falma, de origem islandesa, que significa "tatear", enquanto que a palavra "paixão" remete, em sua etimologia, a "sofrer" ou a "submissão a". Assim, tatear significa se dirigir em direção ao mundo, ser ativo; enquanto paixão remete ao outro aspecto da vida afetiva, que é o de submeter-se ao mundo, ou ser passivo. Tais colocações de Mazis (1999), à luz da filosofia de Merleau-Ponty, apontam para uma reciprocidade entre homem e mundo dentro de uma circularidade em que a expressão do sujeito e a impressão do objeto constituir-se-iam como uma e mesma coisa pela vivência afetiva.

Tais tendências e estados afetivos surgiriam inicialmente nas relações que são estabelecidas pela criança com o meio, sobretudo o humano, já que afetividade e relações intersubjetivas parecem imbricar-se fortemente. Essa proposição é sustentada pela caracterização desenvolvida por Wallon (2007), que descreve e situa a atividade emocional como simultaneamente social e biológica em sua natureza e responsável por realizar a transição entre o estado orgânico do ser e sua etapa cognitiva ou racional. A consciência afetiva, para Wallon, é a forma pela qual o psiquismo emerge da vida orgânica, sobretudo marcada por um caráter predominantemente social, pois forneceria o primeiro e mais forte 
vínculo entre os seres da espécie, inclusive suprindo a insuficiência da articulação motora e cognitiva nos primeiros anos de vida do indivíduo. Segundo Wallon, na ontogênese, o apogeu da afetividade coincide com o período de imperícia máxima do ser, uma vez que ela teria justamente por função supri-la, por meio de sua capacidade de mobilização do outro (Wallon, 2007).

Merleau-Ponty (2001), em suas considerações sobre o fenômeno afetivo, conduz seus argumentos na mesma direção, ao salientar que percepção e conhecimento são sustentados por uma função mais profunda, a qual se encontra em relação estreita com a afetividade. Nesse sentido, Merleau-Ponty pontua que a percepção das coisas depende da personalidade e das relações intersubjetivas que se estabelecem com o meio humano, as quais têm um caráter marcadamente afetivo.

Para dar evidências sobre esse ponto, Merleau-Ponty (2001) descreve um experimento em que se projetou numa tela a imagem de um cachorro que se transformava lentamente em um gato. Os sujeitos de estrutura perceptual considerada rígida não percebiam a mudança, a não ser bem tardiamente, e persistiam em não ver aquilo que ia contra sua primeira percepção do objeto. Demonstraram rejeição a reconhecer os fenômenos de transição, evidenciando dificuldades em reconhecer a ambiguidade presente nas coisas percebidas ou nas ideias. Dessa maneira, haveria, por parte desses sujeitos, a tendência a refletir sua ambiguidade emocional em uma recusa à ambiguidade intelectual e perceptiva.

\section{O APEGO EM DISCUSSÃO}

Dados empíricos e etológicos também destacam a estreita relação entre a biologia e suas ressonâncias na afetividade humana (Bowlby, 1969), pois por estes se verificou que certos modelos do comportamento animal seriam similarmente válidos para a primeira infância do homem. Por meio desses estudos, foi observada a existência de uma estrutura neurofisiológica que funcionaria de modo a sustentar uma tendência original e permanente do sujeito em buscar uma relação com o outro, o que reafirma a conexão proposta por Wallon do psiquismo e suas origens biológicas. O desenvolvimento de tais estudos fundamentou a elaboração da teoria do apego proposta por Bowlby (1969).

Essa teoria visou a evidenciar como surgem e se estabelecem os vínculos sociais por meio de sua base biológica, assim como também acentuar a qualidade afetiva de tal evento. A proposição do apego surgiu, inicialmente, da observação de primatas em que se verificou que a necessidade de contato, a busca de proximidade com a mãe antecipava-se à fome. Verificou-se que, no bebê macaco, a procura 
de nutrição era voluntariamente sacrificada à procura de contato com a mãe e que esse contato lhe assegurava um bem-estar, uma segurança que se configurava como uma emoção de uma força e persistência consideráveis (Harlow, 1965). Assim, partindo dessa perspectiva, o apego refere-se a condutas mais ou menos independentes das necessidades fisiológicas cuja função é essencialmente social: assegurar a interação e cooperação entre os congêneres (Zazzo, 1991). No campo teórico do apego, essa predisposição é considerada como parte de um sistema inato de vinculação à mãe que está ancorado em uma estrutura neurofisiológica e se constitui como uma tendência original e permanente em procurar a relação com o outro. $\mathrm{O}$ apego designaria, dessa forma, um vínculo específico de um indivíduo com o outro. O primeiro vínculo estabelecido é geralmente com a mãe, mas ele pode também ser acompanhado dos vínculos com outros indivíduos e, uma vez formado, tem por natureza a duração e não a contingência, como é observada no caso da dependência, em que o vínculo é mantido, geralmente pelas exigências de uma situação. Os teóricos do apego, sustentados por suas observações e estudos, pontuam, dessa maneira, que a sociabilidade sustentada pelo afeto faz parte do domínio biológico da mesma maneira que a fome, a sede e os elementos de natureza erótica (Zazzo, 1991).

Bowlby (1969) apresenta alguns marcadores para situar a emergência do psíquico sobre a base biológica e o caráter relacional-afetivo desse processo. Assim, Bowlby (1969), baseando sua teoria nos estudos etológicos citados acima, enumerou cinco padrões de comportamento (sucção, abraço, choro, sorriso, ação de seguir), que se estabeleceriam dentro do período de idade que vai dos 9 aos 18 meses e organizar-se-iam em um sistema de regulação e equilíbrio, tendendo a manter a criança em proximidade à mãe. Dentro dessa perspectiva, certas condutas associadas a tal sistema inato de vinculação equivaleriam a outras verificadas em animais. Por exemplo, segundo Bowlby, na criança, o equivalente motor de condutas animais de vinculação seria o sorriso. A conduta do sorriso pertenceria, portanto, de uma só vez, pelo seu duplo papel orgânico e social, à ordem da emoção e à ordem do conhecimento, como sistema primário de reações, meio de vinculação que seria ao mesmo tempo dependente e instrumento de uma autonomia progressiva.

Propondo uma aproximação entre as teorias de Bowlby e Wallon, Gaudron (2007) aponta como convergência entre elas sobretudo a importância inicial dada à figura materna; para Bowlby, em termos de monotropia, ou seja, a tendência que essa figura de apego teria em ocupar uma primazia sobre as outras figuras, e, para Wallon, como órgão organizador da psique da criança. No entanto Gaudron (2007) pontua que Bowlby tende a limitar o aspecto relacional do sujeito ao vínculo materno, estabelecendo este como um sistema linear e binário, 
comentando que Bowlby, de alguma forma, utiliza-se da dimensão social apenas como um lugar necessário para a construção do vínculo de apego. Gaudron (2007) aponta que a dimensão social não tem a mesma definição nem ocupa o mesmo lugar para os autores em questão, pois, para Wallon, o social, embora inclua o aspecto relacional, estende-se para além deste, abrangendo também a perspectiva institucional e cultural. Dessa forma, para Wallon, o social não se resumiria apenas a um objeto de análise, mas a um verdadeiro campo de engajamento e compreensão das relações humanas. A título de ilustração dessa conexão do relacional ao campo mais alargado do social proposto por Wallon, Zazzo (1978), conforme apontado por Almeida (2014), identifica na obra de Wallon três tipos de outro: primeiramente, referem-se àqueles com os quais o indivíduo interage concretamente nas relações interpessoais; além desse, o outro também é referido como conceito geral, que engloba todos os outros em sua pluralidade; e, por fim, o outro íntimo ou socius, que é considerado como o parceiro constante, permanente do Eu na vida psíquica. Sobre este último aspecto do outro, ele também é nomeado por Wallon como "fantasma do outro", que seria um outro - duplo do eu, o segundo termo de um par insolúvel, companheiro permanente do eu, que, na teoria walloniana, teria o papel de intermediário ou de articulação entre o mundo interior e o mundo concreto do ambiente (Wallon, 1975). Segundo Gaudron (2007), esse outro poderia ser identificado, no início da vida psíquica, à figura de apego de que Bowlby fala, acrescentando o fato de que, na teoria walloniana, caberia à criança, ao mesmo tempo, internalizá-la para se diferenciar. Gaudron (2007) salienta que Wallon, ao propor essas consideraçóes, acentua a circunstância de que a vida social e a vida emocional estão dialeticamente e intimamente ligadas.

\section{PHILIPPE ROCHAT: AFETIVIDADE E A ESTRUTURAÇÃO DA CONSCIÊNCIA NO CAMPO INTERSUBJETIVO}

Em uma apreciação mais recente desse campo de estudos, Rochat (2002) também apresenta alguns marcadores que remetem ao estabelecimento do apego, porém procura salientar, em suas considerações, a relação destes com o desenvolvimento do que chamou de coconsciência. Rochat sugere, dessa forma, que o desenvolvimento da consciência reflexiva proviria de uma necessidade de vinculação íntima com o outro, de uma necessidade de proximidade física e psíquica com esse outro. Ele se refere a essa circunstância ao justificar a utilização que faz do termo coconsciência, pois, para ele, a consciência de si só emergiria da relação primária com o outro. Ele pretende, nesse sentido, enunciar, dentro desses conceitos, uma noção de consciência orientada para além de seus aspectos 
cognitivos, remetendo-se aos aspectos socioafetivos que orientariam a criança dentro desse desenvolvimento.

Avançando em suas consideraçôes, o autor sugere que o desenvolvimento da coconsciência realizar-se-ia mediante quatro condições necessárias: a emergência de um si corporal, a reciprocidade afetiva, a absorção do si através do espelho afetivo e, por fim, a emergência da triangulação si-outro-mundo (Rochat, 2002). Partindo desses elementos, a criança desenvolveria, desde os primeiros meses, uma subjetividade crescente, nomeada por Rochat como intersubjetividade. Em conformidade com o exposto, ao contrário de uma consciência de si separada das coisas que a circundam, a criança desenvolveria uma coconsciência de si em relação ao outro.

Em relação ao si corporal, Rochat (2002) pontua que este emergiria a partir dos sistemas sensoriais herdados durante a filogênese e tornar-nos-ia aptos a diferenciar fenômenos externos a nós mesmos. Estaria ligado ao aspecto qualitativo da nossa experiência subjetiva, a qual nos seria dada pela percepção sensível. Rochat afirma que, desde a nascença, e até mesmo durante o estado fetal, o bebê manifesta uma consciência implícita de seu corpo como uma entidade diferenciada entre outras no ambiente. Para ele, esse si corporal do recém-nascido seria um si percebido e não ainda representado no sentido de um eu conceitual.

Porém, para Rochat, seria em torno do segundo mês de vida da criança que ocorreria um primeiro salto qualitativo, no que se refere aos comportamentos do bebê, relevante para a Psicologia do desenvolvimento. Rochat postula que essa ocasião coincidiria, de maneira marcante, com a aparição do sorriso social. Esse evento, segundo o autor, marcaria o verdadeiro início da vida relacional, pois seria a primeira manifestação de uma experiência compartilhada com outro, além de configurar-se como uma experiência de bem-estar. O sorriso orientado seria a primeira mensagem de uma reciprocidade que não é somente ligada aos cuidados e atençôes físicas prestadas ao bebê, pois se trata de uma primeira mensagem afetiva que, de fato, inicia a conversação que a criança terá com o seu entorno social até sua morte. Seria, para ele, o início da coconsciência que marcaria o nascimento do bebê como pessoa, ou seja, entidade que não pode se constituir e se desenvolver senão dentro da troca social e da reciprocidade afetiva. Também seria no decurso do segundo mês de vida que a exploração visual da criança focar-se-ia privilegiadamente sobre os olhos e a boca de outras pessoas, em vez de manter-se em seus traços periféricos; e as imitações precoces tornar-se-iam mais flexíveis e explicitamente voluntárias. Baseando-se nessas consideraçôes, Rochat (2002) afirma que, em torno de seis semanas, o bebê manifesta uma nova atitude em relação aos objetos, a si mesmo e aos outros. Essa 
nova atitude tratar-se-ia de uma atitude contemplativa e recíproca, em oposição a atitude descriminante e imediata do recém-nascido.

Sobre a aspiração do si pelo espelho social, que é o terceiro aspecto presente na formação do que chama de coconsciência, Rochat explicita que se trataria de um fenômeno de ressonância emocional compulsiva do adulto bastante notável em direção à criança e tido como único da espécie humana dentro de toda diversidade de suas organizações familiares e culturais (Gergely \& Watson, 1996). Tal espelhamento tratar-se-ia de uma troca afetiva bidirecional em que o adulto imitaria e refletiria, de maneira exagerada, os estados afetivos do bebê. Esse processo, segundo Rochat, serviria como meio para deflagrar o processo de descentração, apontado como necessário para a formação da coconsciência. Esse processo, portanto, guiaria a criança na direção da contemplação de si no outro. A partir desse jogo de espelhamento afetivo face a face entre bebê e adulto, nasceriam as rotinas, rituais e outras formas de protoconversações dentro das quais cada um dos protagonistas reencontrar-se-ia e identificar-se-ia. Seria nesse contexto que o bebê descobriria o seu ser interpessoal. Esse espelhamento social permitiria à criança objetivar-se em se projetando para fora de sua esfera "privada", sobre a tela e a caixa de ressonância oferecidas pelo adulto.

Wallon (1970) definira essa circunstância de espelhamento proposta por Rochat como "simpatia". Para ele, esse fenômeno surgiria sobre um fundo de mimetismo em que haveria captação, invasão do eu pelo outro. A mímica, nesse contexto, é considerada como um aspecto do sistema que reúne um sujeito ao outro.

$\mathrm{Na}$ sequência de suas considerações sobre a coconsciência, Rochat (2002) também cita que, paralelamente ao desenvolvimento das interações sociais, entre os 2 e 6 meses de idade, os bebês desenvolvem uma forte inclinação pelos objetos físicos, que eles se póem a pegar e manipular de maneira sistemática. Ele aponta que, de maneira geral, é possível observar que a fixação do olhar sobre o outro dentro das trocas face a face tende a diminuir significativamente nessa fase. Tal circunstância parece indicar um maior poder de tratamento da informação perceptiva assim como maior capacidade de memória por parte da criança. Rochat afirma que tais ganhos cognitivos permitiriam à criança uma nova alocação da atenção que daí em diante poderia se dirigir tanto aos outros como às coisas. Para o autor, seria dentro desse contexto que se desenvolveria a antecipação e representação do outro em referência a si e a suas próprias atividades em relação às coisas. Daí emergiria uma nova triangulação entre o bebê, o outro e o mundo entorno e, de acordo com Rochat, seria dessa triangulação que nasceria a comunicação simbólica, pelo uso de signos mais ou menos arbitrários para se comunicar com o outro em referência aos objetos do mundo. Para Rochat, é 
por meio dessa integração que o bebê começará a ter o outro constantemente ao espírito, mesmo enquanto este estiver ausente, uma característica que não o deixará mais.

Pode-se verificar, por essas proposições de Merleau-Ponty, Wallon e Rochat, que a criança, no decorrer de seu desenvolvimento, mais particularmente no que se refere ao período que se estende até os 3 anos de idade, desdobraria, com a contribuição marcante da afetividade, suas interações com o outro em um nível mais profundo, no sentido de que estas seriam interiorizadas e sustentariam o desenvolvimento de sua estrutura psíquica.

Ainda de acordo com essas considerações, Merleau-Ponty (2001) situa a aquisição da linguagem como um fenômeno de identificação, pois aprender a falar corresponderia a desempenhar um certo número de papéis e a assumir condutas nas quais se era expectador anteriormente. A criança, ao reestruturar suas relações com o outro, reestruturaria seu próprio universo. Este se trataria, portanto, de um fenômeno de descentração, porém de uma descentração vivida que se realizaria por uma operação vital e não simplesmente intelectual. Nesse contexto, a criança aprenderia a pensar as relações recíprocas, a distinguir a noção de papel daquela de indivíduo. Ela aprende a relativizar as ações de criança mais nova, mais velha, etc. Ainda aí, afirma Merleau-Ponty, o desenvolvimento intelectual é conduzido por um desenvolvimento vital e afetivo.

Um aspecto relevante levantado por Rochat (2002), tratando dessa questão, e que evidencia uma contribuição original do autor que, assim como Wallon, procura evidenciar a afetividade como fenômeno de destaque no estabelecimento dos vínculos interpessoais, refere-se à sua proposição de que, durante a integração do olhar do outro dentro de suas explorações do ambiente, o bebê manifestaria, sobretudo no plano afetivo, uma nova tendência que se consolidaria como motivação central e que seria a busca da aprovação social.

O autor vai ainda mais longe ao postular que, desde o início da vida psíquica, a criança desenvolveria, de maneira primordial, aquilo que é frequentemente associado à antítese da razão, a paixão ou uma desrazão afetiva, guiada por uma necessidade relacional incontornável. Segundo ele, essa busca está presente seja no sentido da criança que começa a falar e funcionar simbolicamente, seja no sentido do adolescente em sua busca paradoxal de uma identidade ou também aquela do sujeito em suas escolhas na fase adulta. Tal processo, portanto, não a deixará mais e desenvolver-se-á em direção da formação de uma consciência de si em relação ao outro. Ao nível do comportamento, essa nova consciência manifestar-se-ia sob a forma proativa de um empreendimento sistemático de sedução que conduziria a criança a agir de maneira desarrazoada e fantasmagórica. Ao nível das trocas 
com o outro, essa revolução psicológica traduzir-se-ia pela aparição de toda uma gama de comportamentos de caráter proativo guiados sempre pela paixão de uma proximidade afetiva com os outros. Tal acontecimento marcaria os inícios da sedução ativa e seletiva do bebê em relação ao mundo social que o circunda. Tais jogos tomariam frequentemente formas que desafiam a razão. É nesse sentido que se pode dizer que, paralelamente aos progressos do pensamento lógico e racional que continuam a ser documentados pelos numerosos pesquisadores, e que se situam na linha de trabalho de Piaget, a criança desenvolveria também, talvez de maneira primordial, uma capacidade de sedução que frequentemente a conduziria à desrazão.

Marques (2012) realiza uma elaboração sobre esse tema em sua dissertação, apresentando a leitura que Merleau-Ponty faz de Scheler, que parece de alguma forma iluminar a questão da desrazão afetiva destacando-a como elemento que perpassa a filosofia de Merleau-Ponty. Marques (2012) aponta que o empreendimento merleaupontiano de realizar a crítica das metafísicas dualistas é atravessado pela noção de intencionalidade afetiva que o filósofo toma emprestado de Scheler. De acordo com Marques (2012, p. 63), Scheler busca "fazer da fenomenologia dos valores um domínio de pesquisa autônomo, que não dependa daquele que funda a lógica”, conferindo a essa intencionalidade a tarefa de dar um sentido à vida afetiva, artística e religiosa, situando-a não no domínio da teoria do conhecimento, mas naquele da vida do desejo. Marques (2012) retoma Saint Aubert, o qual explicita que:

O empreendimento de Scheler [. . .] é a tentativa de introduzir na filosofia uma análise que não trataria mais apenas do conhecimento, mas da "lógica do coração", da qual fala Pascal, que Scheler define como intencionalidade emocional, e que é original em relação à intencionalidade do conhecimento (Saint Aubert apud Marques, 2012, p. 55).

Tais colocaçóes parecem dialogar com a perspectiva de Rochat, no sentido de explicitar essa intencionalidade como algo impulsionador na vida do sujeito, atuando em um terreno estranho à intencionalidade intelectual, um terreno característico que Scheler chama de essências "alógicas", as quais se abrem a valores próprios (Merleau-Ponty, 1935). Merleau-Ponty (1935) descreve essa particularidade ao comentar que "O amor é um ato orientado que tem um sentido, que tem uma espessura intencional", assim como outros sentimentos, como a simpatia ou o ódio, que teriam como natureza própria a propensão de visar a algum termo outro que eles mesmos (Merleau-Ponty, 1935, p. 20). Complementando essas colocaçóes, Marques (2012) pontua que, na última fase da obra merleaupontiana, ocorre uma aproximação entre a formulação da intencionalidade emocional e o desejo em que sucede a instituição de uma 
filosofia do laço, a qual "Vê o desejo como 'uma relação de ser', e como o horizonte impensado de todo laço" (Saint Aubert apud Marques, 2012, p. 150).

E, no entanto, que não se entenda tal destaque no caráter emocional e afetivo de nossas relações, anunciado sobretudo com base na Psicologia infantil, como um desmentido da razão ou simplesmente seu contrário. Ao contrário, desde a Fenomenologia da percepção, Merleau-Ponty (1999) destaca o caráter "irracional" da própria razão, falando, contra Piaget, da "crença bárbara" da criança de pertencimento comum de todos a um mesmo mundo. Piaget, conforme destaca Merleau-Ponty, chama essa crença de "egocentrismo infantil", a ser superado logicamente, quando a criança percebe que a sua visão de mundo é a sua perspectiva e não a de todo mundo, e que a conquista da objetividade supóe o diálogo e a discussão destas. Ora, diz Merleau-Ponty (1999), o fato é que essa crença acompanha a razão adulta também e é ela que fundamenta a possibilidade do acordo de perspectivas a partir da comunicação com os outros (p. 474).

Rochat (2002) também se reporta a esse campo de ideias ao comentar que o desenvolvimento dessa dimensão referenciar-se-ia a um mundo essencialmente subjetivo e fantasmagórico, acrescentando ainda que se trataria de um domínio em que haveria a primazia dos olhares dos outros sobre si, denotando seu caráter marcadamente relacional.

\section{CONSIDERAÇŌES FINAIS}

Partindo das considerações apresentadas no decorrer das discussōes levantadas pela revisão de literatura apresentada neste trabalho, que se apoiaram sobretudo nas contribuiçôes de Merleau-Ponty, Henri Wallon e Philippe Rochat, este estudo exploratório procurou destacar a importância da investigação da dimensão afetiva, nomeadamente no período inicial da vida, que se coloca como um âmbito produtivo em termos de insights sobre o campo do desenvolvimento, propondo a rearticulação de nossa compreensão sobre o fenômeno da vinculação humana e da formação da consciência do sujeito.

As considerações aqui expostas levam a pensar cada vez mais que a autonomia do sujeito não se coloca em oposição à codependência deste em relação aos seus congêneres. Salienta-se que esses "outros" podem assumir diferentes papéis nos diferentes momentos do desenvolvimento do sujeito assim como significativas ressonâncias na configuração dos seus afetos. Temos como exemplo a figura parental e sobretudo a materna, que foi aqui sugerida como objeto de vinculação inicial e elemento de destaque na mediação da criança em relação ao mundo, assim como outras que não foram aqui citadas diretamente, como aquelas 
pertencentes ao núcleo familiar e aos âmbitos de socialização mais ampla. Dessa maneira, a dimensão afetiva surge, nesse contexto, como meio privilegiado de acesso a esse outro por sua capacidade de sintonia, contágio e aproximação direta, formando e estabelecendo os vínculos de diferentes matizes e qualidades. Um aspecto a ser sublinhado a partir dessas descrições é o de que as integrações das diferentes dimensões do sujeito dependem dessas articulações que demonstram envolver um crescente senso de compartilhamento.

As proposições de Merleau-Ponty e Rochat sobre desrazão e sedução, particularmente, buscam salientar que as relaçóes entre afetividade e inteligência são mais profundas do que se tem até o momento considerado, deixando entrever a existência de uma lógica própria aos afetos dentro da relação intersubjetiva que precisa ser melhor explorada e compreendida de modo a se alcançar um melhor entendimento do âmbito desenvolvimental humano. 


\section{REFERÊNCIAS}

Almeida, A. R. S. (1999). A emoção na sala de aula. Campinas: Papirus. (Coleção Papirus Educação).

Almeida, L. R. (2014). A questão do Eu e do Outro na psicogenética walloniana. Estudos de Psicologia, 31(4), 595-604.

Arantes, V. A. (2003). Afetividade na escola: alternativas teóricas e práticas. São Paulo: Summus.

Bowlby, J. (1969). Attachment and loss. London: Hogard.

Folscheid, D. \& Wunenburger, J-J. (1997). Metodologia filosófica. São Paulo: Martins Fontes.

Gaudron, Z. C. (2007). John Bowlby et Henri Wallon: des chevauchements possibles dans l'attachement, de la théorie à la clinique. Toulouse : ERES.

Gergely, G. \& Watson, J. S. (1996). The social biofeedback theory of parental affect-mirroring: the development of emotional self-awareness and self-control in infancy. International Journal of Psycho-Analysis, 77(6), 1181-1212.

Harlow, H. F. (1965). Behavoir of non-human primates. New York: Academic.

Marques, P. P. (2012). Merleau-Ponty: acerca da intencionalidade. (Dissertação de Mestrado). Universidade Federal de Minas Gerais, Faculdade de Filosofia e Ciências Humanas, Belo Horizonte. Recuperado a partir de https://repositorio. ufmg.br/bitstream/1843/BUOS-8TYJQY/1/dissertacao_fev_2012_paulo_ pimenta_marques.pdf

Mazis, G. A. (1999). Merleau-Ponty: l'habiter et les emotions. Alter Revue de Phénoménologie, 7, 285-349.

Merleau-Ponty, M. (1935). Christianisme et ressentiment. La Vie Intellectuelle, 7 (36), 278-306.

Merleau-Ponty, M. (1999). A fenomenologia da percepção. São Paulo: Martins Fontes.

Merleau-Ponty, M. (2001). Psychologie et pédagogie de l'enfant: Cours de Sorbone: 1949-1952. Lagrasse: Verdier. 
Mota, M. E. (2005). Psicologia do desenvolvimento: uma perspectiva histórica. Temas em Psicologia, 13(2), 105-111.

Rochat, P. (2002). Naissance de la co-conscience. Intellectica, 34(1), 99-123.

Sisto, F. F., Boruchovitch, E., \& Fini, L. T. D. (2001). Dificuldades de aprendizagem no contexto psicopedagógico. Petrópolis: Vozes.

Tassoni, E. C. M. (2000). Afetividade e aprendizagem: a relação professor aluno. GT Psicologia da Educação. In Anais, 23 Reunião Anual da Anped, Anuário 2000. Caxambu: Anped. Recuperado a partir de http://23reuniao.anped.org. $\mathrm{br} /$ textos/2019t.PDF

Wallon, H. (1970). De l'acte à la pensée : essai de psychologie comparée. Paris Flammarion.

Wallon, H. (1975). A psicologia genética. In A. Rabaça (Trad.), Psicologia e educação da infância. (pp. 9-21). Lisboa: Estampa.

Wallon, H. (1995). Uma concepção dialética do desenvolvimento infantil. Petrópolis: Vozes.

Wallon, H. (2007). A evolução psicológica da criança. São Paulo: Martins Fontes.

Zazzo, R. (1991). L'attachement : une nouvelle théorie sur les origones de l'affectivité. In J. P. Bronckart, \& P. Mounoud (Orgs.), L'attachement. Paris: Delachaux et Niestlé, Neuchatel. 